\title{
Declarative Questions
}

\author{
Christine Gunlogson \\ University of California, Los Angeles
}

\section{Introduction}

\subsection{Overview}

Consider the three sentences in (1):
a. Is it raining?
b. It's raining?
Rising polar interrogative
c. It's raining.
Rising declarative
Falling declarative

The polar interrogative in (1a) is the prototypical way to ask a yes/no question. (1c) is a declarative with falling intonation, the canonical device for making a statement. The declarative with rising intonation, indicated by the question mark in (1b), is superficially more similar in function to (1a) than (1c). Thus, a familiar use of rising declaratives is as a kind of polar question:

$$
\text { It's raining? } \approx \text { Is it raining? }
$$

Intuitively, the rise seems to impart questioning force to what would otherwise be a statement. But the story cannot be as simple as (2) suggests. It turns out that declarative questions are subject to contextual restrictions that don't apply to their interrogative counterparts. For example, declarative questions are not appropriate in situations where the questioner is supposed to be neutral or ignorant:

[at a committee hearing]

a. Are you a member of the Communist party?

b. \#You're a member of the Communist party?

c. \#You're a member of the Communist party.

Furthermore, unlike interrogatives, declarative questions cannot be used "out of the blue". (4a) is felicitous as an initial remark, without any preceding discussion of persimmons, while (4b) and (4c) are odd in the same situation.

(4) [to coworker eating a piece of fruit]
a. Is that a persimmon?
b. \#That's a persimmon?
c. \#That's a persimmon.

The fact that falling declaratives (indicated with a period in (3c)-(4c)) are also unacceptable as questions in these circumstances is intuitively unsurprising but 
nonetheless significant. Given that rising declaratives pattern with falling declaratives rather than interrogatives in the above examples, it is natural to seek an explanation for the constraints in the common element of declarative form, and that is exactly the approach I will take here.

At the same time, the intuition that rising declaratives are more natural as questions than falling ones is undeniable. Examples like (5), where the rising declarative patterns with the interrogative, support that intuition:
A: The king of France is bald.
B's response:
a. Is France a monarchy?
b. France is a monarchy?
c. \#France is a monarchy.

Since (5b) and (5c) differ only in their intonational contour, we must look to the rise for an explanation of the question-like behavior of rising declaratives. In the account given here, the explanation crucially depends not just upon the meaning of the rise but on its interaction with declarative form and with the context.

The goal of the paper is to characterize the distribution of declaratives as questions and provide a compositional analysis from which both the restrictions and the questioning use follow. Section 2 introduces distributional data and formulates two of the empirical generalizations on which the analysis is based:

(6) Declaratives are not neutral; they convey a bias that interrogatives lack.

(7) Rising declaratives, like syntactic interrogatives, fail to commit the Speaker to their propositional content.

Section 3 implements a contextual treatment of bias and neutrality, using an articulated version of Stalnaker's (1978) Common Ground to track each participant's commitments individually. Section 4 gives an update semantics for rising and falling declaratives from which (6) and (7) follow, accounting for examples like (3) and (5).

The restriction exemplified by (4) is treated in Section 5, where I present data supporting the descriptive generalization in (8):

(8) Declaratives can be used as questions only in contexts where the Addressee is understood as publicly committed to the proposition expressed.

The guiding hypothesis in explaining the restriction is that questions must be uninformative with respect to the Addressee - a requirement that declaratives can only meet in certain contexts. The analysis predicts, correctly, that in addition to their familiar "echoing" function, rising declaratives may be used to question presuppositions and inferences taken to follow from the Addressee's public position, whether or not such inference finds its basis in a preceding utterance. 


\subsection{Assumptions}

I rely on the minimal-pair methodology exemplified in (3)-(5): rising declaratives are compared with interrogatives on the one hand and with falling declaratives on the other, holding constant the lexical content and nuclear accent placement. Interrogatives, too, can have rising or falling intonation, but I restrict attention to the rising variety. The terms (polar) interrogative and declarative refer to syntactic sentence types, while (polar) question is the name of a pragmatic category to which utterances of both interrogatives and declaratives can belong.

Rising and falling intonation are indicated with the standard orthographic devices '?' and '.', respectively. I count as a "rise" any contour whose tail (i.e., post-nuclear portion) is non-falling and which ends at a point higher than the nuclear accent. Similarly, a "fall" is non-rising and ends at a point lower than the nuclear accent. These categories are adapted from Gussenhoven 1983 but can be expressed in other systems as well. For example, the above description of the rise fits the tunes $\mathrm{L}^{*} \mathrm{H} \mathrm{H} \%, \mathrm{~L}^{*} \mathrm{H} \mathrm{L} \%, \mathrm{~L}^{*} \mathrm{~L} \mathrm{H} \%$, and $\mathrm{H}^{*} \mathrm{H} \mathrm{H} \%$ in the system of Pierrehumbert 1980, as modified in Beckman and Pierrehumbert 1986.

Gussenhoven's system posits three basic contour shapes, the rise, the fall, and the fall-rise, with variations expressed in terms of modifications to each type. I ignore the fall-rise and the inventory of modifications to the basic contours.

\section{Distributional generalizations}

\subsection{Declarative bias}

This section documents ways in which rising declaratives pattern with falling ones, differing from interrogatives. The central observation is that declaratives are unacceptable wherever the Speaker is expected to remain ignorant or neutral. As (9) shows, declaratives cannot be used to elicit information in an unbiased way:

[in a job interview]

a. Have you been convicted of a felony?

b. \#You've been convicted of a felony?

c. \#You've been convicted of a felony.

(10) illustrates that the issue raised by a declarative question cannot be regarded as open or unsettled, liable to go either way. In fact, in (11) the rising declarative cannot be described as a question at all, even though the construction is one that accepts a root clause, as the subject-auxiliary inversion in (11a) demonstrates.

(10) It's an open question.

a. Did she lie to the grand jury?

b. \#She lied to the grand jury.

c. \#She lied to the grand jury. 
(11) a. The question is, does he have the money?

b. The question is, \#he has the money?

c. The question is, \#he has the money.

Interrogatives, but not declaratives, can extend a line of inquiry using if so or if not, as in the question from a health insurance form in (12a).

(12) Are you married?

a. If so, does your spouse have health insurance?

b. \#If so, your spouse has health insurance?

c. \#If so, your spouse has health insurance.

Declaratives make poor speculative questions, i.e., questions designed to instigate thought or discussion without necessarily being answered or answerable. (13a) might lead into a discussion of the JFK assassination without committing the Speaker to any particular view; (13b)-(13c) cannot be used to the same effect.
a. Did Oswald act alone?
b. \#Oswald acted alone?
c. \#Oswald acted alone.

As is already evident, the restrictions on declarative questions extend beyond standard "information question" contexts. A particularly clear illustration can be seen in (14), where the interrogative functions as a polite request for action rather than for information. Declaratives do not share this function.
a. Can you (please) pass the salt?
b. \#You can (please) pass the salt?
c. \#You can (please) pass the salt.

The descriptive generalization I advance for the examples so far is given in (6):

(6) Declaratives are not neutral; they convey a bias that interrogatives lack.

In offering (6) as a descriptive generalization I also offer an implicit hypothesis about the use of interrogatives in the contexts illustrated - namely, that certain functions of interrogatives involve at least the appearance of neutrality. I won't attempt to justify this hypothesis explicitly, which would require case-by-case study of the various uses seen above. Rather, I will take (6) as a reasonable working description, seeking a characterization of the notions of neutrality and bias with the expectation that they will ultimately be useful in understanding the range of discourse functions available for interrogatives as well as declaratives.

The flip side to the patterns seen so far is that declaratives are useful when bias rather than neutrality is called for. When it comes to contributing new information, bias is a good thing. This is a given for falling declaratives, the prototypical way to offer a piece of news. But rising declaratives, too, have 
informative potential for many speakers, as seen in (15). ${ }^{1}$ (See Pierrehumbert 1980 for a similar contrast.) Interrogatives do not share this function.

a. \#Is my name Carl? \#Will I be your waiter tonight?

b. My name is Carl? I'll be your waiter tonight?

c. My name is Carl. I'll be your waiter tonight.

The main concern of this paper is the use of declaratives as questions; but the possibility of informative use will be allowed for by the analysis.

There are other systematic distinctions between declaratives and interrogatives, including the fact that interrogatives, but not declarative questions, support polarity items like any and ever (Hirst 1983, Huddleston 1994):
a. Is anybody home?
b. \#Anybody's home?
c. \#Anybody's home.

Such facts do not fit in any obvious way under the generalization in (6), but they do support the general view defended here - namely, that declarative questions are not simply a variant of interrogatives, but have their own distinct properties.

\subsection{Lack of Speaker commitment}

A second crucial observation is that rising declaratives are more natural as questions than falling ones. In this section I support the intuition empirically by showing that rising declaratives pattern in certain ways with interrogatives. The generalization advanced is that rising declaratives, like interrogatives, fail to commit the Speaker to their propositional content. This point emerges in comparison with falling declaratives, which evidently do commit the Speaker.

First note that rising declaratives, like interrogatives, allow for readings in which the Speaker is understood to be skeptical about the proposition expressed. In (17), either an interrogative or a declarative may be used to acknowledge and/or elliptically reiterate A's utterance; but only (a) and (b) are compatible with B's follow-up remark, which suggests that B remains doubtful about the alleged improvement. The falling declarative in (17c) conveys overt agreement with A's opinion, and thus has the effect of inconsistency with the skeptical follow-up.

[A\&B are looking at a co-worker's battered and dented car]

A: His driving has gotten a lot better.

B's response:

a. Has it? I don't see much evidence of that.

b. It has? I don't see much evidence of that.

c. It has. \#I don't see much evidence of that.

This skeptical reading of rising declaratives is well known, and is often assumed to be connected to their "echoing" function. But it would be a mistake to assume 
that rising declaratives are inherently skeptical (or inherently echoing, for that matter). Rising declaratives, like interrogatives, also allow for readings in which the Speaker is understood as routinely accepting the proposition expressed, as illustrated in (18), where the falling declarative is acceptable as well.
A: That copier is broken. B's response:
a. Is it? Thanks, I'll use a different one.
b. It is? Thanks, I'll use a different one.
c. (Oh), it is. Thanks, I'll use a different one.

Example (5), repeated from Section 1.1, does not echo A's utterance but rather questions one of its presuppositions. Again, the interrogative and rising declarative are fine, while the falling declarative is not.

A: The king of France is bald.

B's response:

a. Is France a monarchy?

b. France is a monarchy?

c. \#France is a monarchy.

Like the earlier examples, (5a)-(5b) are compatible with either skepticism or acceptance by the Speaker. The follow-up remark provides the clue to the Speaker's attitude. By themselves, (5a)-(5b) are noncommittal, imposing no constraints on interpretation of the Speaker's position.

The final observation of this section is that rising declaratives, like interrogatives, may make the point that the Addressee, rather than the Speaker, is in a position to know whether the proposition expressed is true. Consider (19):
a. Is shoplifting fun?
b. Shoplifting's fun?
c. \#Shoplifting's fun.
[\# as an insinuation about the Addressee]

Under the right circumstances, asking (19a) or (19b) can be a sly way to communicate that the Addressee is known to shoplift. The answer given by the Addressee is immaterial; the damage is done by the question itself, which seems to carry an assumption on the level of a presupposition that the person addressed is knowledgeable on the subject. (See Hudson 1975 for a similar suggestion.) What makes the insinuation work so well above is the predicate fun, which calls for subjective evaluation. (Compare Is shoplifting a crime?/Shoplifting's a crime?, which lack the effect.) It generally takes personal experience to judge whether an activity is fun. Thus, if the Addressee is presumed knowledgeable about whether shoplifting is fun, it will also be presumed that the Addressee has shoplifted.

The important point at present is that the (a) and (b) examples of (19) do not convey anything about the Speaker's larcenous habits. By comparison, the 
most natural reading of the falling declarative in (19c) portrays the Speaker as the source of information, suggesting that it is the Speaker who has shoplifted.

The twin generalizations that emerge in this section are given in (20)-(21):

(20) Rising declaratives, like interrogatives, fail to commit the Speaker to their propositional content.

(21) Falling declaratives do commit the Speaker to their propositional content.

It follows from (20) that rising declaratives, like interrogatives, allow for a range of Speaker attitudes to be attributed. Falling declaratives, on the other hand, are compatible only with attitudes consistent with commitment.

\subsection{Reconciling bias with lack of commitment}

The outline suggested by the data so far is as follows:

- A declarative expresses (some degree of) commitment to its content, consistent with interpretation of declarative questions as having an element of 'assertiveness' or 'bias'. (See, e.g., Bolinger 1957, Huddleston 1994.)

- The rise expresses lack of commitment to its propositional content, consistent with interpretation as a question.

Equally intuitively, these two generalizations seem contradictory as stated. The challenge to be addressed in this section is how to reconcile them in a principled way that leads to testable predictions about distribution.

The hypothesis I will implement is given informally in (22)-(23):

(22) Rising declaratives commit the Addressee to the proposition expressed.

(23) Falling declaratives commit the Speaker to the proposition expressed.

In compositional terms, I take declaratives to express commitment to their propositional content $\mathrm{p}$, where commitment rules out the alternative, $\neg \mathrm{p}$. The intonational component specifies which participant is committed: the Addressee with a rise, the Speaker with a fall. Rising declaratives do fail to commit the Speaker to $\mathrm{p}$. But rising declaratives also express commitment to $\mathrm{p}$ on the part of the Addressee, allowing for an understanding of the bias.

In the account to follow, bias is characterized in contextual terms. The use of a (rising or falling) declarative with propositional content $\mathrm{p}$ ensures that the context is one in which the participants cannot easily come to agreement on $\neg p$. By committing one participant to $p$, the declarative rules out $\neg p$ as a mutual assumption, effectively conveying a bias toward $p$.

The idea that rising vs. falling intonation is related to a Speaker/Addressee distinction has precedents in the intonational literature, though none are developed in the particular direction taken here. In recent work, Steedman 2000 proposes that the $\mathrm{H} \%$ vs. L\% boundary tone distinction (using the Beckman and Pierrehumbert system) correlates with 'ownership' of the content expressed. The 
proposal of Merin and Bartels 1997 that the rise 'alienates choice to Alter' while the fall 'appropriates choice for Ego' offers a related idea as well. Noh's 1998 Relevance-Theoretic discussion of 'echo questions' relies on the idea of attributing the thought expressed to the Addressee, although Noh does not single out intonation as a factor. The present account is compatible in a broad way with these suggestions and can be seen as a development of the shared core notion of tying an intonational contrast to a Speaker/Addressee distinction.

\section{The discourse context}

I begin with the familiar notion of the Common Ground (Stalnaker 1978). Under Stalnaker's classic treatment, the Common Ground (hereafter CG) is a set of propositions representing what the participants in a discourse take to be mutually believed, or at least mutually assumed for the purposes of the discourse. I assume, as Stalnaker does, a framework in which a proposition is construed as a set of worlds, the worlds of which it is true, leading to the following characterization:

$\mathrm{CG}_{\{\mathrm{A}, \mathrm{B}\}}=\{\mathrm{p} \in \wp(\mathrm{W}): \mathrm{p}$ is a mutual belief of the discourse participants $\mathrm{A}$ and $\mathrm{B}\}$

Equivalently, the context can be construed as the set of worlds of which the mutual beliefs are true, i.e., $\cap \mathrm{CG}$ (in Stalnaker's terminology, the context set).

The mutual beliefs constituting the CG are, crucially, mutual and not just shared. Beliefs that remain private, and beliefs that the participants happen to have in common without mutually realizing it, do not qualify. The contents of the $\mathrm{CG}$ thus depend crucially on who the participants are and what they know about each other's beliefs. (24) makes that dependency explicit by incorporating mention of the participants in the definition. This is a departure from usual practice but does not introduce any new assumptions.

The step needed for the present analysis is to separate out the beliefs mutually attributed to each participant. (25) accomplishes this task, defining a more articulated version of the $\mathrm{CG}$ in terms of public belief without making any essential changes to the basic conception.

(25) Let $\mathrm{DC}_{\mathrm{A}}$ and $\mathrm{DC}_{\mathrm{B}}$ be sets of propositions representing the public beliefs of $\mathrm{A}$ and $\mathrm{B}$, respectively, where:

a. $\mathrm{p}$ is a public belief of $\mathrm{A}$ iff ' $\mathrm{A}$ believes $\mathrm{p}$ ' is a mutual belief of $\mathrm{A}$ and $\mathrm{B}$

b. $\mathrm{p}$ is a public belief of $\mathrm{B}$ iff ' $\mathrm{B}$ believes $\mathrm{p}$ ' is a mutual belief of $A$ and $B$

The set of propositions associated with each participant represents that participant's public beliefs, or discourse commitments (DC) - public in the sense that that person is mutually recognized as committed to them. All mutual beliefs are public, but a public belief of an individual does not have to be mutual.

The context can now be represented as an ordered pair $\left.\angle \mathrm{DC}_{\mathrm{A}}, \mathrm{DC}_{\mathrm{B}}\right\rangle$, replacing $\mathrm{CG}_{\{\mathrm{A}, \mathrm{B}\}}$ (still derivable as $\mathrm{DC}_{\mathrm{A}} \cap \mathrm{DC}_{\mathrm{B}}$.) Or, equivalently and more 
conveniently, the context can be construed as an ordered pair of sets of worlds, analogous to Stalnaker's context set. In (26) I adopt the latter construal. Here the abbreviation $c s$ stands for the commitment set of an individual, the set of worlds of which that individual's public beliefs are true.

(26) Let a discourse context $\mathrm{C}$ be $\left\langle\mathrm{cs}_{\mathrm{A}}, \mathrm{cs}_{\mathrm{B}}>\right.$, where:

a. $\mathrm{A}$ and $\mathrm{B}$ are the discourse participants

b. $\operatorname{cs}_{A}(C)=\{w \in W: A$ 's public beliefs are all true of $w\}$

c. $\operatorname{cs}_{B}(C)=\{w \in W$ : B's public beliefs are all true of $w\}$

Just as the Common Ground is recoverable given $\mathrm{DC}_{\mathrm{A}}$ and $\mathrm{DC}_{\mathrm{B}}$, the Stalnakerian context set is recoverable from $<\mathrm{cs}_{\mathrm{A}}, \mathrm{cs}_{\mathrm{B}}>$ as $\mathrm{cs}_{\mathrm{A}} \cup \mathrm{cs}_{\mathrm{B}}$.

To illustrate how the divided context works, consider a discourse in which A and B publicly disagree on some point. Suppose that A has said that cats make better pets than dogs, while $\mathrm{B}$ favors dogs. Let $\mathrm{q}$ stand for the proposition expressed by Cats make better pets than dogs. Clearly $\mathrm{q}$ is not a mutual belief, since A and B are in disagreement on this very point. Of course $\neg \mathrm{q}$ is not a mutually held proposition either, since A's belief is in conflict with it. Still, q does figure indirectly in the Common Ground, which records their mutual beliefs about each other's positions. That is, the fact that A believes q itself has the status of a mutual belief, as does the fact that B believes a proposition entailing $\neg \mathrm{q}$ (assuming, as I do here, that the participants' statements reflect their beliefs).

The formalism just introduced makes the descriptive task easy in this situation: $\mathrm{q}$ is a discourse commitment of $\mathrm{A}$ 's (that is, $\operatorname{cs}_{\mathrm{A}} \subseteq \mathrm{q}$ ), and $\neg \mathrm{q}$ is a discourse commitment of B's $\left(\mathrm{cs}_{\mathrm{B}} \subseteq \mathrm{W}\right.$-q). Neither q nor $\neg \mathrm{q}$ can become a mutual belief in this context, at least not without revision. Let us call both $\mathrm{q}$ and $\mathrm{W}-\mathrm{q}$ controversial with respect to the context. The relevant notions are defined below.

$\mathrm{p}$ is a commitment in $\mathrm{C}$ of an individual discourse participant $\mathrm{X}$ iff $\mathrm{cs}_{\mathrm{X}} \subseteq \mathrm{p}$.

$\mathrm{p}$ is a joint commitment in $\mathrm{C}$ iff $\mathrm{p}$ is a commitment of all participants.

$\mathrm{p}$ is unresolved in $\mathrm{C}$ iff neither $\mathrm{p}$ nor $\mathrm{W}-\mathrm{p}$ is a joint commitment.

$\mathrm{p}$ is controversial in $\mathrm{C}$ iff $\mathrm{W}-\mathrm{p}$ is a commitment of at least one discourse participant and $\mathrm{p}$ is unresolved in $\mathrm{C}$.

A second type of situation in which q may be a public belief without being mutual is the following. Suppose A commits to $q$, as before. Consider the discourse state before $\mathrm{B}$ makes any response. At this point $\mathrm{q}$ is not a joint commitment, though it may become one without further ado if $\mathrm{B}$ indicates agreement. W-q is not a joint commitment, either, but its status is different from that of $\mathrm{q}$. While $\mathrm{q}$ just needs ratification by $\mathrm{B}$ to become a joint commitment, $\mathrm{W}-\mathrm{q}$ is not eligible as a joint commitment at all, given that $\mathrm{A}$ has already committed to q. In an obvious way the context is biased toward $q$; only q can be admitted as a mutual belief without requiring (non-monotonic) revision.

This simple and intuitive notion of contextual bias is what I will use in accounting for the bias of declaratives. The definitions are given in (31)-(33). 
(31) $\mathrm{C}$ is empty iff there is at least one $\mathrm{cs}_{\mathrm{X}}$ in $\mathrm{C}$ such that $\mathrm{cs}_{\mathrm{X}}=\varnothing$.

(32) C is biased toward p iff $\mathrm{C}$ is not empty, W-p is controversial, and $\mathrm{p}$ is not controversial.

(33) $\mathrm{C}$ is neutral with respect to $p$ iff $\mathrm{C}$ is not empty and neither $\mathrm{p}$ nor $\mathrm{W}-\mathrm{p}$ is controversial.

Contextual bias exists if mutual agreement on $\mathrm{p}$ is possible (without revision) while mutual agreement on $\mathrm{W}-\mathrm{p}$ is ruled out due to an existing commitment to $\mathrm{p}$ by at least one discourse participant. If the context is in a neutral state with respect to $\mathrm{p}$, then joint commitment to either $\mathrm{p}$ or $\mathrm{W}-\mathrm{p}$ is possible in principle.

The contextual states introduced here are not particular to the analysis of declaratives. They offer a general way to talk about bias and neutrality that is potentially useful for handling other phenomena as well (e.g., tag questions, negative polar interrogatives, and discourse particles). The next step in the present analysis is to make the link with the semantics of rising and falling declaratives.

\section{Sentence and locution meaning}

\subsection{Declaratives}

The basic idea to be implemented in this section, following the tradition of update semantics, is that the meaning of a sentence is its context change potential, its CCP (Heim 1982 and others). Here, the CCP of a sentence is defined in terms of an update to a substructure of the context, the commitment set (cs) of an individual participant. The rise and fall serve to identify the individual cs to be updated, given an utterance context, i.e., a context in which participants can be identified in the roles of Speaker and Addressee.

I use the term locution, abbreviated $\mathrm{L}$ or $\mathrm{S}$, to designate the linguistic expression comprising a sentence of a given type plus the rise or fall, retaining the more traditional sentence for expressions not specified for intonational contour. This and other notational conventions are summarized in (34).
a. $\uparrow \mathrm{S}_{\mathrm{decl}}$ : rising declarative locution
b. $\downarrow S_{\mathrm{decl}}$ : falling declarative locution
c. $\uparrow S_{\text {interr }}$ : rising polar interrogative locution
d. $S$ : ranges over $\left\{S_{\text {decl }}, S_{\text {interr }}\right\}$
e. L: ranges over $\left\{\uparrow S_{\text {decl }}, \downarrow S_{\text {decl }}, \uparrow S_{\text {interr }}\right\}$
f. 令: ranges over $\{\uparrow, \downarrow\}$
g. $\operatorname{cs}_{\mathrm{X}}$ : ranges over $\left\{\mathrm{cs}_{\mathrm{A}}, \mathrm{cs}_{\mathrm{B}}\right\}$

The CCP of a declarative is defined with respect to an individual $\mathrm{cs}_{\mathrm{X}}$, as in (35), where the descriptive content is the proposition expressed by the declarative:

$$
\operatorname{cs}_{\mathrm{X}}+\mathrm{S}_{\mathrm{decl}}=\left\{\mathrm{w} \in \mathrm{cs}_{\mathrm{X}} \text { : the descriptive content of } \mathrm{S}_{\mathrm{decl}} \text { is true of } \mathrm{w}\right\}
$$


CCPs for rising and falling locutions are given in (36) and (37), respectively:

$$
\mathrm{C}+\uparrow \mathrm{S}=\mathrm{C}^{\prime} \text { such that: }
$$

a. $\operatorname{cs}_{\text {Addr }}\left(C^{\prime}\right)=\operatorname{cs}_{\text {Addr }}(C)+S$

b. $\operatorname{cs}_{\mathrm{Spkr}}\left(\mathrm{C}^{\prime}\right)=\operatorname{cs}_{\mathrm{Spkr}}(\mathrm{C})$

$\mathrm{C}+\downarrow \mathrm{S}=\mathrm{C}^{\prime}$ such that:

a. $\operatorname{cs}_{\mathrm{Spkr}}\left(\mathrm{C}^{\prime}\right)=\operatorname{cs}_{\mathrm{Spkr}}(\mathrm{C})+\mathrm{S}$

b. $\operatorname{cs}_{\text {Addr }}\left(\mathrm{C}^{\prime}\right)=\operatorname{cs}_{\text {Addr }}(\mathrm{C})$

$\operatorname{cs}_{\mathrm{Addr}}$ is a function from an utterance context to either $\operatorname{cs}_{\mathrm{A}}$ or $\mathrm{cs}_{\mathrm{B}}$, whoever is in the role of Addressee at the time of utterance; similarly for $\mathrm{Cs}_{\mathrm{Spkr} .}{ }^{2}$

Combining the elements above, we arrive at the result in (38) for a rising declarative locution, and (39) for the falling version:

$\mathrm{C}+\uparrow \mathrm{S}_{\mathrm{decl}}=\mathrm{C}^{\prime}$ such that:

a. $\operatorname{cs}_{\text {Spkr }}\left(\mathrm{C}^{\prime}\right)=\operatorname{cs}_{\mathrm{Spkr}}(\mathrm{C})$

b. $\operatorname{cs}_{\text {Addr }}\left(C^{\prime}\right)=\operatorname{cs}_{\text {Addr }}(C)+S_{\text {decl }}$

$\mathrm{C}+\downarrow \mathrm{S}_{\mathrm{decl}}=\mathrm{C}^{\prime}$ such that:

a. $\operatorname{cs}_{\mathrm{Spkr}}\left(\mathrm{C}^{\prime}\right)=\operatorname{cs}_{\mathrm{Spkr}}(\mathrm{C})+\mathrm{S}_{\mathrm{decl}}$

b. $\operatorname{cs}_{\text {Addr }}\left(\mathrm{C}^{\prime}\right)=\operatorname{cs}_{\text {Addr }}(\mathrm{C})$

In each case the declarative component makes the same contribution: eliminating worlds from a commitment set of which the descriptive content is not true. The rise or fall is a function mapping a sentence meaning to a context update function that applies it to an individual commitment set, leaving the other commitment sets unchanged. Locution meaning follows compositionally, as summarized in (40):

$$
|\mathrm{L}|=|\hat{\mathrm{s}}|(|\mathrm{S}|)=\text { function from } \mathrm{C} \text { to } \mathrm{C}^{\prime} \text { such that } \mathrm{cs}_{\mathrm{X}} \text { of } \mathrm{C}^{\prime}=|\mathrm{S}|\left(\operatorname{cs}_{\mathrm{X}}\right) \text { and } \mathrm{C}^{\prime}
$$
is otherwise identical to $\mathrm{C}$

Following Heim 1983, I treat updates as partial functions, defined only for contexts in which presuppositions are satisfied. A context admits a sentence only if presuppositions are met (or accommodatable). I generalize the notion of admittance to locutions and contexts as well sentences and commitment sets, as defined in (41)-(42). Finally, I assume that presuppositions must be satisfied with respect to joint commitments rather than individual sets, as (42) provides.

(41) $\quad \operatorname{cs}_{X}$ admits $S$ iff for all $r$ such that $r$ is a presupposition of $S, \operatorname{cs}_{X} \subseteq r$.

(42) C admits is iff for all $\operatorname{cs}_{X}$ in $C, \operatorname{cs}_{X}$ admits $\mathrm{S}$.

The operations $\mathrm{cs}_{\mathrm{X}}+\mathrm{S}$ and $\mathrm{C}+\mathrm{L}$ are defined only if $\mathrm{cs}_{\mathrm{X}}$ admits $\mathrm{S}$ and $\mathrm{C}$ admits $\mathrm{L}$, respectively. This approach distinguishes between presuppositional content and primary descriptive content in a way that seems accurate: presuppositions cannot be controversial, as the propositional content proper can be. 
A locution is consistent only if the update does not result in an empty cs:

$\mathrm{L}$ is consistent with a context $\mathrm{C}$ iff $\mathrm{C}$ admits $\mathrm{L}$ and $\mathrm{C}+\mathrm{L}$ is not empty.

\subsection{Interrogatives}

Consistent with (36), I assume that an interrogative with rising intonation operates on the commitment set of the Addressee. Interrogatives, however, do not commit the Addressee to their content, or the Speaker either. In fact, interrogatives differ crucially from declaratives in not expressing commitment at all. The CCP of an interrogative is thus just an identity function on the targeted commitment set.

$$
\mathrm{cs}_{\mathrm{X}}+\mathrm{S}_{\text {interr }}=\mathrm{cs}_{\mathrm{X}}
$$

Effectively, $\mathrm{C}+\uparrow \mathrm{S}_{\text {interr }}=\mathrm{C}$. Note that the treatment of presuppositions generalizes to interrogatives, a significant advantage given that interrogatives carry the same presuppositions as their declarative counterparts.

This treatment does not do justice to our intuitions about interrogatives. Intuitively, a context in which an interrogative has been uttered is not identical to one lacking the interrogative utterance. I assume that polar interrogatives do have non-trivial effects on aspects of the discourse context not represented here. See Büring 1995, Roberts 1996, and Groenendijk 1999 for examples of enriching the contextual representation to model interrogative updates. Proposals agree, however, on the point that matters here - polar interrogatives do not commit any participant to their descriptive content. ${ }^{3}$

\subsection{Locutionary bias and neutrality}

The bias or neutrality of a locution can be derived from the contextual states produced, as (45)-(46) state.

Given a locution $\mathrm{L}$ with descriptive content $\mathrm{p}$ and a context $\mathrm{C}$ that admits $\mathrm{L}$ :

(45) L is neutral with respect to $\mathrm{C}$ iff $\mathrm{C}+\mathrm{L}$ is neutral with respect to $\mathrm{p}$.

(46) $\mathrm{L}$ is biasing with respect to $\mathrm{C}$ iff $\mathrm{C}$ is neutral with respect to $\mathrm{p}$ and $\mathrm{C}+\mathrm{L}$ is biased toward $\mathrm{p}$.

It follows from (35), together with (45), that no use of a declarative can be neutral. There are two types of outcome when a (consistent) declarative is uttered. Either the declarative has the effect of eliminating some worlds from the cs of some participant, resulting in a state of controversy or bias; or the declarative is uninformative. A declarative can only be uninformative, however, if the context is already non-neutral, that is, if worlds of which the content is not true are already absent from the targeted cs. Similarly, it follows from the identity-function definition of an interrogative CCP in (44) that no occurrence of an interrogative can be biasing. The generalizations in (47)-(48) thus have the status of theorems: 
(47) No is $\mathrm{S}_{\mathrm{decl}}$ is neutral with respect to any $\mathrm{C}$.

(48) No is $S_{\text {interr }}$ is biasing with respect to any $C$.

Note that it does not follow that all declaratives are biasing, nor that an interrogative locution is always neutral. A locution is biasing only if it effects a transition from a neutral to a biased context. Similarly, interrogatives qualify as neutral only when uttered in a neutral context.

The unacceptability of declaratives illustrated in Section 2.1 follows directly from (47). By hypothesis, those examples involved situations requiring the Speaker to maintain (at least the appearance of) neutrality. Use of a declarative, whatever the intended function of the move, is guaranteed to result in a non-neutral context, in violation of the expectation of neutrality.

The examples of Section 2.2 are also accounted for. Since the Speaker uttering a rising declarative does not commit herself to the content uttered, the range of attitudes shown to be possible is perfectly consistent with the proposal.

\subsection{Entailment, uninformativeness, and vacuousness}

Entailment is defined as a relation between a context and a locution, as in (49), or between a sentence and a commitment set, as in (50).

$$
\begin{aligned}
& \mathrm{C} \vDash \mathrm{L} \text { iff } \mathrm{C} \text { admits } \mathrm{L} \text { and } \mathrm{C}+\mathrm{L}=\mathrm{C} \\
& \mathrm{cs} \vDash \mathrm{S} \text { iff cs admits } \mathrm{S} \text { and } \mathrm{cs}+\mathrm{S}=\mathrm{cs}
\end{aligned}
$$

The idea behind the definitions in (49)- (50), extending Groenendijk 1999, is that a sentence or locution is entailed when its effect has already been achieved.

A notion that will be important in the next section is uninformativeness:

(Un)informativeness with respect to a commitment set

(51) is is informative with respect to $\operatorname{cs}_{X}(C)$ iff $C$ admits is $S$ and $\operatorname{cs}_{X} \not=\mathrm{S}$.

(52) i $S$ is uninformative with respect to $\operatorname{cs}_{X}(C)$ iff $C$ admits is and $\operatorname{cs}_{X} \vDash S$.

Derivatively, a locution may be (un)informative with respect to the context:

(53) $\mathrm{S}$ is informative with respect to $\mathrm{C}$ iff it is informative with respect to at least one cs in $\mathrm{C}$.

(54) $\mathrm{S}$ is uninformative with respect to $\mathrm{C}$ iff it is uninformative with respect to every cs in $\mathrm{C}$.

According to (51)-(52), a locution that is entailed by a context may still be informative. Informativeness is defined in terms of the potential effect of $\mathrm{S}$ on a cs, without regard to whether the locutionary update actually operates on that cs.

Interrogatives are always uninformative. Declaratives, however, are potentially informative, even in contexts where they are entailed. For a declarative locution to be uninformative with respect to the context, it must be the case that 
its content is already a joint commitment of both participants. To describe this sort of case I define one final notion, that of vacuousness:

$L$ is vacuous with respect to $C$ iff $p$ is a joint commitment in $C$, where $p$ is the descriptive content of $\mathrm{L}$.

Any locution that is vacuous with respect to a context is also uninformative in that context and entailed by it. But an uninformative locution is not necessarily vacuous; interrogatives aren't vacuous just because they are uninformative.

Note that a rising interrogative (as well as a declarative), may be consistent with a (non-empty) context in which the Addressee is already committed to its descriptive content. Intuitively, an interrogative is redundant in such circumstances. Given that the Addressee's commitment to $\mathrm{p}$ is already a matter of public record, the interrogative seems to be calling for a response that is bound to be uninformative. It is common practice in modeling discourse to focus on informativeness in terms of the literal content of utterances. Hence, many models of discourse incorporate rules that prohibit uninformative statements, along with barring interrogatives whose answers would be uninformative. For the present account, however, it is crucial that the uninformativeness (or redundancy) of an utterance be understood as distinct from its felicity. The fact is that what we may think of as 'confirming questions', i.e., questions to which an answer has already been given, are felicitous. Examples (17)-(18) demonstrate that, and Section 5.2 will provide further examples.

In this paper, which focuses on questions, the property of uninformativeness defined above is of more concern than informativeness. To preview the argument of the next section, the claim I will defend with respect to declaratives is that they are interpretable as questions only when uninformative with respect to the Addressee's commitment set. The data to be introduced in Section 5.2 will show that this generalization is accurate.

Restricting attention to uninformative rising declaratives allows me to sidestep the issue of what it means for a speaker to make a move that has the effect of modifying the Addressee's public commitments. I assume that such moves are possible. This is the door I will leave open for future accounts of the informative use of rising declaratives exemplified in (15), without, however, pursuing the topic further in this paper.

\section{Questioning}

\subsection{Uninformativeness and questioning: a hypothesis}

The update semantics for rising and falling declaratives, together with the definitions of contextual bias and neutrality given in Section 3, account for the observed bias of declaratives as well as the differences between rising and falling declaratives documented in Section 2.2. Two matters remain to be addressed: 
- What is the connection between the meaning proposed for rising declaratives - committing the Addressee to the proposition expressed - and the natural interpretation of rising declaratives as questions?

- Why can't declarative questions be used out of the blue? (Recall example (4).)

In this section I claim that these two points are related, and sketch the outline of a treatment of questioning; see Gunlogson 2001 for a more complete discussion.

The hypothesis guiding the analysis is that uninformativeness with respect to the Addressee is necessary for an utterance to qualify as a polar question:

(56) An utterance of a locution $\mathrm{L}$ is a polar question in $\mathrm{C}$ only if $\mathrm{L}$ is uninformative with respect to $\operatorname{cs}_{\mathrm{Addr}}(\mathrm{C})$.

Since interrogatives are always uninformative, they are guaranteed to satisfy (56). Declaratives are a different matter. Since a declarative is potentially informative, whether a particular declarative utterance is informative with respect to the Addressee's commitments or not crucially depends on the context in which it is uttered. Declaratives satisfy (56) only in contexts in which the Addressee's public commitments entail the proposition expressed. In such contexts, the Speaker cannot be construed as intending to tell the Addressee that $\mathrm{p}$ holds. My claim is that this public clue to the Speaker's intentions is prerequisite for the success of a declarative question.

In the next section I support the claim empirically by showing that declaratives can function as questions only where they meet the criterion of uninformativeness. For clarity I give a version of the condition tailored to declarative questions in (57) and call it the Contextual Bias Condition:

Contextual Bias Condition on declarative questions

(57) An utterance of $\hat{s} S_{\text {decl }}$ with descriptive content $\mathrm{p}$ is interpretable as a polar question in $\mathrm{C}$ only if $\operatorname{cs}_{\text {Addr }}(\mathrm{C}) \subseteq \mathrm{p}$.

The Contextual Bias Condition is quite strong in a particular way: it demands that the Addressee's commitment be a public belief. Compare (57) to the weaker alternative stated in (58):

Alternative version (to be rejected)

(58) An utterance of $\$ S_{\text {decl }}$ with descriptive content $\mathrm{p}$ is interpretable as a polar question in $\mathrm{C}$ only if it is plausible from the Speaker's point of view that the Addressee believes $\mathrm{p}$.

The important difference between (57) and (58) is that the latter allows for the Speaker's private information about the Addressee's private belief state to license the rising declarative question, while the former insists that the Addressee's belief (and hence the Speaker's awareness of it) must be public.

For the explanation advanced above, motivating the Contextual Bias Condition in terms of uninformativeness, the stronger version is crucial. The reason is simply that the Speaker's private beliefs, being private, cannot give the 
Addressee the kind of clue to the Speaker's intention that public uninformativeness provides. When the Addressee's prior commitment to $p$ is mutually recognized, the Addressee can be sure that the Speaker's use of an uninformative declarative is deliberate, and pragmatic reasoning about intentions can proceed accordingly. We need not rely exclusively on this conceptual argument, however. (57) will be supported empirically in the next section.

The Contextual Bias Condition is put forward as a necessary but not sufficient condition for questioning. For discussion of sufficiency conditions for questioning, see Gunlogson 2001, where a distributional notion of 'question' is argued for. The full argument cannot be presented here, but it can be noted in the examples throughout this paper that rising declaratives, in contexts where they function in ways we are inclined to call questioning, are interpretable in the same ways as their interrogative counterparts in those contexts. The solution suggested by this pattern is simple: rising declaratives operate as polar questions when (and because) their contextual requirements and effects overlap with those of polar interrogatives. Falling declaratives do not overlap in the same way, and their diminished aptitude as questions follows.

\subsection{The Contextual Bias Condition on declarative questions}

The data in this section center around the observation that declaratives cannot readily be used as questions 'out of the blue'. That is, interrogatives may initiate discourses in ways that the corresponding declarative questions may not. (59a), but not (59b-c), can be used to strike up a conversation with a stranger about his dog. Similarly, (60a), but not (60b) or (60c), is a standard way of beginning a telephone conversation in the hopes of speaking to Laura.

[to passerby walking a dog]

Pardon me, but...

a. Is that a Weimaraner?

b. \#That's a Weimaraner?

c. \#That's a Weimaraner.

(60) [initiating a phone conversation]
a. Is Laura there?
b. \#Laura's there?
c. \#Laura's there.

The awkwardness of the declaratives in (59)-(60) does not follow from the account of declarative bias. We expect, in light of that account, that a question asked via a declarative will be non-neutral. But here, unlike the cases exemplified in Section 2, there is no plausible expectation of neutrality from the Speaker to be violated by the declarative question. Suppose, for instance, that the Speaker of (59b) privately knows or suspects that the dog is a Weimaraner. In fact, it is difficult to avoid making that assumption, even for the interrogative in (59a), given that the Speaker has chosen to ask a polar question about a particular breed 
rather than simply asking what kind of dog it is. Why should it be so odd for the Speaker to ask a non-neutral declarative question, in effect conveying her own positive bias by way of conveying an expectation that the Addressee will agree?

Furthermore, it is not sufficient for the Speaker to have a private reason for believing that the Addressee believes p. The Speaker in (59), in addition to suspecting that the dog is a Weimaraner, may also suspect that the owner knows what kind of dog it is; owners of purebred dogs very often do. It seems to follow that the Speaker can reasonably assume that the Addressee believes the dog to be a Weimaraner (though nothing in the context allows the Addressee to reconstruct that reasoning.) The problem is that adding these background suppositions about the Speaker's private assumptions fails to improve the declarative question. The stronger demand of the Contextual Bias Condition must be met.

One of the agreeable consequences of that condition is that the "echo" uses of rising declaratives fall out naturally. The situation where the Addressee has already stated the content presented by the declarative question is just a special case subsumed under the more general condition given in (57).

It cannot be claimed, however, that declarative questions must always echo some preceding utterance. We have already seen that presuppositions may be questioned, a result that is compatible with the Contextual Bias Condition but not with an echoing requirement. Another compatible result is that the Speaker can use a declarative question to present an inference interpretable as a consequence of the Addressee's position, as shown in (61)-(62). In these examples all three locutions are acceptable, and all suggest that A's speech act has led the Speaker to the conclusion expressed by the descriptive content.

$$
\begin{aligned}
& \text { A: Jon has to leave early. } \\
& \text { B's response: }
\end{aligned}
$$

a. Will he miss the party then?

b. He'll miss the party then?

c. He'll miss the party then.
A to caller: Mom, I'll call you back tomorrow, OK?
Caller:
a. Are you too busy to talk to your mother?
b. You're too busy to talk to your mother?
c. (I see.) You're too busy to talk to your mother.

Bartels 1997 and Noh 1998 also make the point that sentences functioning as 'echoes' are not limited to repeating previously uttered content.

The propositions expressed by the Speaker in (61)-(62) clearly are not logical entailments of the sentence uttered previously. They're not even (necessarily) conversational implicatures, given that the preceding sentence may not ordinarily be taken to imply what the Speaker has chosen to represent as mutually inferrable from its utterance. I will assume that in these cases the declarative is accommodated as a question by making the necessary contextual adjustment to meet the Contextual Bias Condition. The adjustment required is the 
portrayal of the proposition expressed by the declarative as following from the Addressee's commitments. If we take $p$ to be the content of the declarative question, what must be accommodated as a joint commitment of the participants is $\mathrm{q} \rightarrow \mathrm{p}$, where $\mathrm{q}$ is a relevant public commitment of the Addressee's that serves as the basis for the inference.

The clearest evidence that declarative questions are not inherently echoes comes from contexts where there is no preceding utterance to echo at all. Compare (63) and (64). In (63), the declaratives are infelicitous, as expected.

(63) Robin is sitting in a windowless computer room with no information about current weather conditions when another person enters.

Robin says to the newcomer:
a. Is it raining?
b. \#It's raining?
c. \#It's raining.

The revised version shows that the absence of an appropriate utterance cannot be the decisive factor in the infelicity of (63). In (64) there is pertinent extralinguistic evidence - the wet raingear - that makes possible to accommodate the Addressee's public commitment, and the declaratives are accordingly improved.

(64) Robin is sitting in a windowless computer room when another person enters. The newcomer is wearing a wet raincoat and boots. Robin says:
a. Is it raining?
b. It's raining?
c. (I see that/So) It's raining.

The contrast between (63) and (64) is clear, and it establishes decisively that declarative questions do not require a linguistic antecedent.

Summarizing this section, the facts show that no amount of tinkering with assumptions about private knowledge, private belief, or private evidence will render a declarative question felicitous in the absence of relevant public evidence. In its most obvious manifestation, the public evidence for the Addressee's belief is the Addressee's own utterance. But the evidence need not be linguistic in nature, as long as the Contextual Bias Condition can be met (or accommodated). The result arrived at empirically in this section is thus in agreement with the hypothesis advanced on more conceptual grounds in Section 5.1.

\section{Summary}

In this paper I have given a compositional account of rising and falling declaratives, focusing on their use as questions and introducing a body of observations illustrating restrictions on such use. Declaratives (in contrast to interrogatives) express commitment to their propositional content. Rising vs. falling intonation is responsible for attribution of the commitment to the 
Addressee vs. the Speaker, respectively. The result is an inherent contextual 'bias' associated with declaratives, distinguishing them from interrogatives.

The picture that emerges is one in which intonational and sentence type meaning constrain how utterances with particular content function in discourse but do not determine their function. Understanding the questioning use of declaratives does not reduce to a problem of assigning 'question force' but requires a deeper investigation of the complex interaction between context and formal elements. Declaratives function as questions only in contexts that provide the appropriate sort of support for conveying the Speaker's questioning intention.

An important feature of the approach taken here is that the contextual restrictions are peculiar to the use of declaratives as questions. We do not expect to find declaratives intended as statements to be subject to them. The point is abundantly clear for falling declaratives, whose uses are obviously not confined to questioning. For rising declaratives, the existence of informative uses, like (15), becomes less mysterious. The current analysis cannot be said to predict the existence of such uses, but at least it doesn't predict their nonexistence - giving it a head start on any account in which the rise is directly associated with a questioning function or an attitude of uncertainty on the part of the Speaker.

\section{Endnotes}

${ }^{1}$ The question mark in (15b) marks rising intonation, not a questioning function.

${ }^{2}$ It should be clear that the meaning posited for the rise and fall is indexical in nature, on a par with the expressions such as $I$, you, the Speaker, and the Addressee and amenable to the same sort of analytical treatment.

${ }^{3}$ By the descriptive content of an interrogative I mean the proposition expressed, in an obvious way - e.g., It is raining for the interrogative Is it raining.

\section{References}

Bartels, Christine 1997. Towards a Compositional Interpretation of English Statement and Question Intonation. Ph.D. dissertation, University of Massachusetts Amherst.

Beckman, M., and J. Pierrehumbert 1986. Intonational structure in Japanese and English. Phonology Yearbook 3, 15-70.

Beun, R.J. 2000. Context and Form: Declarative or Interrogative, that is the Question. In Bunt, H. and W. Black, eds., Abduction, Belief and Context in Dialogue. Studies in Computational Pragmatics. Amsterdam: John Benjamins.

Bolinger, Dwight L. 1957. Interrogative Structures of American English: The Direct Question. American Dialect Society No. 28. University of Alabama Press, Birmingham.

Büring, Daniel. 1995. The 59 $9^{\text {th }}$ Street Bridge Accent. Ph.D. dissertation, Tübingen. (Published 1997, Routledge.) 
Büring, Daniel. 1999. “Topic”, in P. Bosch and R. van der Sandt, eds., Focus. Cambridge: Cambridge University Press.

Groenendijk, Jeroen. 1999. The Logic of Interrogation (Classical Version). In Tanya Matthews and Devon Strolovitch, eds., SALT IX 109-126, Ithaca, NY: Cornell University.

Gunlogson, Christine 2001. True to Form: Rising and Falling Declaratives as Questions in English. Ph.D. dissertation, University of California, Santa Cruz.

Gussenhoven, Carlos 1983. A semantic analysis of the nuclear tones of English. Reproduced by the Indiana University Linguistics Club.

Heim, Irene 1982. The Semantics of Definite and Indefinite Noun Phrases. Ph.D. dissertation, University of Massachusetts, Amherst.

Heim, Irene 1983. On the Projection Problem for Presuppositions. In Flickinger, D., et al., eds., Proceedings of the Second West Coast Conference on Formal Linguistics. Stanford: Stanford University Press.

Hirst, D.J. 1983. Interpreting intonation: a modular approach. Journal of Semantics 2 2:171-181.

Huddleston, Rodney 1994. The contrast between interrogatives and questions. $J$. Linguistics 30, 411-439.

Hudson, Richard A. 1975. The Meaning of Questions. Language 51:1.

Merin, Arthur and Christine Bartels 1997. Decision-Theoretic Semantics for Intonation. Arbeitspapiere des SFB 340, Bericht Nr. 88, Juni 1997.

Noh, Eun-Ju 1998. Echo Questions: Metarepresentation and Pragmatic Enrichment. Linguistics and Philosophy 21:603-628.

Pierrehumbert, J.B. 1980. The phonology and phonetics of English intonation. Ph.D. dissertation, MIT.

Pierrehumbert, Janet B. and Julia Hirschberg 1990. The meaning of intonational contours in the interpretation of discourse. In P.R. Cohen, J. Morgan, and M.E. Pollack, eds., Intentions in communication. Cambridge, MA: MIT Press, pp. 271-311.

Roberts, Craige. 1996. "Informative Structure in Discourse: Towards an Integrated Formal Theory of Pragmatics", in J.H. Yoon and A. Kathol, eds., OSU Working Papers in Linguistics 49: Papers in Semantics.

Steedman, Mark 2000. Information Structure and the Syntax-Phonology Interface. Linguistic Inquiry 31:4.

Stalnaker, R. 1978. Assertion. In P. Cole (ed.) Pragmatics: Syntax and Semantics, Volume 9. New York: Academic Press. 